\title{
chapter news
}

\section{University of Alabama in Huntsville}

The March meeting was held at the University of Alabama in Huntsville's (UAH) atmospheric sciences classroom in the Global Hydrology and Climate Center (GHCC). The chapter is a recently formed student chapter representing a broad cross section of members reflecting the diverse scientific makeup of the GHCC and the surrounding community. Since its inception in April 1996, monthly meetings have been held on a regular basis.

Chapter President Jeff Lerner summarized old and new chapter business during the first segment of the meeting. After chapter business, Brian Peters, warning coordination meteorologist at the Birmingham National Weather Service Forecast Office (NWSFO), presented some unpublished slide photographs of the 24 January 1997 F2 tornado in Tuscaloosa, Alabama.

For the remainder of the meeting, the 15 people in attendance were treated to a presentation by Ron Przybylinski, scientific operations officer at the St. Louis NWSFO, of some severe weather cases that took place in the St. Louis area. The first case he covered was the afternoon storm of 19 April 1996 in the eastern Missouri-central Illinois area. He showed some radar reflectivity and velocity slides from the WSR$88 \mathrm{D}$ in St. Louis. He pointed out the time evolution of these storms, many of which split to produce rightmover tornadic thunderstorms. At one time, he said that more than six storms were observed to be "splitting." The left-moving storms produced baseball- sized hail. The right movers produced several tornadoes (category F3 and less) and displayed the classic hook-echo reflectivity structures. According to Przybylinski, this day was described as "the parade of tornadoes" across central Illinois by some. One of the features associated with this day was the storm development north of a cool moist cloudy region over southeastern Missouri. He pointed out that the hook-echo features appeared approximately 45 minutes after a mesocyclone was detected at a radar elevation angle of $1.5^{\circ}$.

Przybylinski also showed some radar data and storm damage slides from the 22 September 1993 tornado event to the east of St. Louis, in which two tornadoes were observed. One of the features of these tornadoes was the evolution of the vortices at the apex of the bow structure evident in the NEXRAD imagery.-Jeff Lerner.

\section{Wright Memorial}

Chapter President Jason Tuell welcomed over 35 members to the meeting on 6 March 1997.

Tuell introduced the evening's guest speaker, Lt. Col. Andy White from the NOAA WSR-88D NEXRAD Operational Support Facility in Norman, Oklahoma. White told the group that the WSR-88D Program is a triagency cooperative effort with the Department of Defense, Federal Aviation Administration, and the NWS. He mentioned that the NWS is undergoing a modernization program to improve the quality and reliability of its products and services. The keystone of this modernization is the new Doppler Weather Surveillance Radar (Model WSR-88D). The WSR-88D excels in detecting the severe weather events that threaten life and property from early detection of damaging winds to estimating rainfall amounts for use in river and flood forecasting.

White continued his presentation with a short history of the Next Generation Weather Radar (NEXRAD). He noted that the "next" part is a misnomer, as the system was the first part of the NWS's modernization program to achieve steady-state status and has been in the field for years. Besides the original WSR-88D in Norman, Oklahoma, which was delivered in May 1990, the first set to be accepted was at Melbourne, Florida, in March 1992. According to White, there are now over 160 systems operating across North America, Hawaii, Guam, and Puerto Rico. He showed maps indicating the WSR-88D installed base and noted three areas of particular interest where new systems are going in this year: western Arkansas, northeast Alabama, and northern Indiana.

White concluded his talk by discussing the current and future hardware and software configurations of the WSR-88D. He described how the NEXRAD program office is taking the system away from a proprietary nature to an open system architecture. The open 
system concept will both extend the lifetime and greatly enhance the capabilities of the NEXRAD system by improving warnings, addressing evolving requirements, controlling life cycle costs, and taking advantage of advances in technology. White presented examples of results from two future technologies currently being examined in Norman: the dual polarization and storm detection animation.-Pat Hayes.

\section{Kansas City}

The chapter held a meeting on 26 February 1997. The meeting began with some announcements. Jerry Griffin brought the members up to date on plans for providing judges to the Kansas City Science Fair. Chapter President Pat Cooper then announced the latest snowfall total for the snowfall contest participants. She then thanked member Donna Tucker for attending a meeting for local chapters that was held at the 77th AMS Annual Meeting. Cooper also reminded members that officer nominations were needed for the next chapter election. She previewed future meetings and asked for meeting ideas.

The featured speaker for the evening was Phil Clark, who is with NWS's ASOS (Automated Surface Ob- serving System) program office. Clark said that he serves in a public relations capacity for the program. He was able to give a complete overview of the systems capabilities. He also talked about other possible applications for the ASOS data, including possible future uplinks for pilots, and uses in air pollution monitoring. Clark explained how ASOS compares with European systems. He also explained how aviation standards set the requirements for what type of data needs to be collected by the various sensors. He went into detail on how time sampling was used so that it could give data that would estimate what the weather was like in a five-mile radius of an airport.

Clark covered some of the other capabilities that will likely be added to the system, including sunshine and lightning detection sensors. He mentioned that snow depth will continue to be one capability that the system will lack. He said that budget constraints should not effect the ongoing improvement program since it is funded through the year 2002. By the end of 1998, all the planned ASOSs are expected to be up and running, bringing the total to 942 units.

The chapter held a meeting on 20 March 1997 at the engineering firm of Black and Veatch. The meet-

\section{Difficult Precipitation Measurement?}

\section{Measure Precipitation Type Measure Precipitation Occurrence}

\section{Measure Precipitation Intensity Measure Precipitation Accumulation}

The ScTi ORG-715 Optical Precipitation Sensor measures rain and snow like no other rain gauge. The optical technology means that your measurements will be accurate and reliable. Our customers use the ORG-715 to monitor flood conditions,

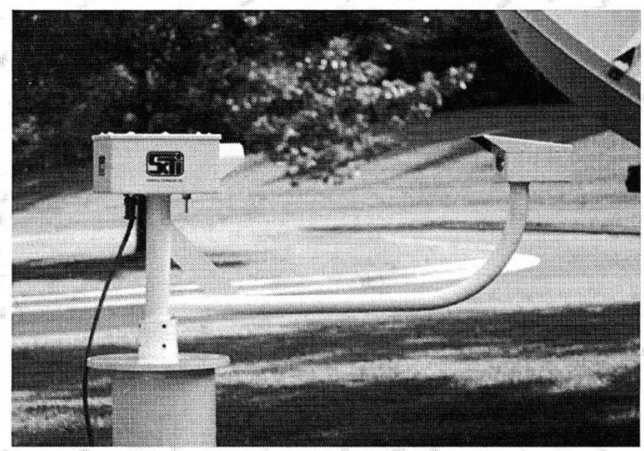

control railroad switch heaters, close telescope bay doors, study rain-induced satellite signal loss, provide shipboard and buoy rain measurements, and determine precipitation type along highways. The choice of applications is endless!

For complete details, literature, and application information please contact us. Or, visit the ScTi home page on the world wide web at http:/www.netrail.net/ scti/ for immediate information

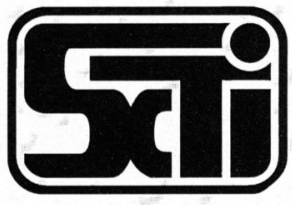

Scientific Technology, Inc.

205 Perry Parkway, Suite 14 Gaithersburg, MD 20877 USA

Phone: (301) 948-6070

Fax: (301) 948-4674

E-mail: scti@netrail.net

Web: http://www.netrail.net/ scti/ 
ing was called to order by Chapter President Pat Cooper, who began with a report of the latest snowfall reading of 26.4 inches for those participating in the chapter's snowfall contest. Cooper also briefly covered the tentative plans for upcoming meetings. She mentioned a survey she was developing to get feedback about the chapter from the members.

Chapter Member Janice Bunting made an announcement about a project on which the Kansas City Science Museum is working. It will host a science city festival sometime in September and would like to have a booth with some sort of an atmospheric experiment for children. Bunting said that anyone interested can contact her for more information. Member Bill Winkert announced that the downtown airport will conduct a 70th anniversary celebration on 17-18 August and would like to include a weather booth or display related to the airport's history. Member Carolyn Kloth of the Aviation Weather Center announced that the center is working on a history project of aviation weather.

The evening's main presentation then began, with the topic being a recap of some of the more notable winter storms of the 1996/97 season. The speaker for this presentation was Pete Browning, the science and operations officer for the Pleasant Hill, Missouri, NWS. Bunting began the talk by showing computer graphics depicting some of the snow climatology for the Kansas City area. The storm that occurred on $23 \mathrm{Oc}-$ tober 1996 stood out as a definite anomaly in the data. He used the initial analysis of gridded data to show some of the key weather features that were occurring with this storm. He noted that one of the key elements that turned the rain over to snow was an infusion of drier air being advected into the storm from the north. This drier air provided enough evaporative cooling to produce the changeover, plus helped to deepen and slow the progress of the system.

The other storm that Browning discussed occurred on 27 January of 1997 . He noted that the pattern involved with this storm was markedly different from the October event. He explained that a shallow cold air mass was already in place and the upper-level system was much weaker than the earlier storm. At the beginning of the event, there was a nose of abovefreezing temperatures at the $850-\mathrm{mb}$ level. Browning noted that a key ingredient in this event was a reinforcing surge of low-level cold air that was moving in from the north. This deepened the colder air and helped to provide the additional lift needed to sustain a longer event.-Pat Cooper.

\section{Southeastern Wyoming}

The first meeting of the chapter convened on 15 January 1997 at the NWS, Cheyenne. Fourteen people attended.

The first order of business was to elect officers. The officers elected for 1997 were Linda Engebretson, president; Mike Weiland, vice president/treasurer; and Julie Adolphson, secretary.

Representatives from the UCAR COMET Program presented information on the COMET programs. Greg Byrd listed the four COMET areas to be outreach projects between universities and NWS offices and postdoctoral fellowships, multimedia-based education COMET modules, and classroom-based education residence courses. For 1997 two courses will be offered to NWS employees: hydrometeorology and COMAP. Byrd said that the COMET program will begin focusing on teletraining and Web materials. He announced that the COMET Web site is: http://www.comet. ucar.edu

Tony Mostek presented the NWS Satellite Training Program. He discussed the philosophy of satellite training, the use of digital data in forecast offices, and the satellite Web site at COMET. He also showed highlights of the first satellite module and helped forecasters key in on the most important aspects of this module. Mostek discussed the future of satellite training, including the plans to increase Web presence and conduct more teletraining.

Doug Wesley presented the convective matrix module and discussed how to best use it in forecasting. He also gave a preview of the AAnticipating Storm Structure and Evolution@ module, which will be available soon. His presentation included animations of theories of storm evolution and module organization. Wesley showed that the organization of the module will include theory, conceptual models, case studies, and exercises.

Julie Adolphson discussed COMET case studies and how they can be used in training and research programs. She said that COMET has released six cases and has two more that are about to be completed and released. COMET uses the CODIAC system to distribute these cases, which are 1-3 Gbytes in length. The cases include radar, satellite, model, and observational data.

The chapter convened its second meeting of 1997 on 18 February at the University of Northern Colorado's Michener Library. There were 26 people in attendance. A total of $\$ 22.00$ was collected from 8 members. 
John Weaver, NESDIS/CIRA/CSU, presented 30second and 1-minute imagery from GOES-9. His presentation began with a historical overview of the U.S. weather satellite program and proceeded into a discussion of current capabilities. Weaver presented data from a tornadic thunderstorm on 31 May 96, and he discussed all the available imagery channels on the GOES-9 satellite.-Julie L. Adolphson.

\section{Central Oklahoma}

A group of more than 50 members and guests attended the 20 February 1997 meeting. During the business portion of the meeting, Dave Schultz, chair of the new science fair committee, suggested that the chapter purchase six NOAA weather radios to award as prizes at upcoming science fairs. Members voted that first- and second-place weather-related winners at the Oklahoma City Regional, East Central Regional, and State Science and Engineering Fairs be given a choice of a weather radio or a one-year subscription to Weatherwise as prizes. In other business, Chapter Treasurer Charlie Crisp reported that the chapter now has 128 members.

Chapter Vice President Fred Carr introduced Don Wyckoff of the Oklahoma Archeological Survey as the speaker for the evening. Wyckoff presented a slide show on habitation in Oklahoma before, during, and after the most recent ice age (19 000 years ago). He discussed evidence that not only animals, such as mastodons, mammoths, ground sloths, American lions, bison, camels, and horses but also humans were roaming the present-day state of Oklahoma more than 10000 years ago. Wyckoff said that his research suggests that the extinction of these animals $10500-11500$ years ago was not due to humans killing them but rather due to a prolonged period of dry conditions.

Approximately 40 people attended the 6 March 1997 meeting at the National Severe Storms Laboratory (NSSL) in Norman.

Chapter President Kit Wagner read a report from Dave Schultz, chair of the science fair committee. Schultz and Bob Hamilton judged the Oklahoma City Regional Science and Engineering Fair on 5 March at the Omniplex.

Their report noted one winning project: “The Relationship between Precipitation and Creek Flow," by Maya Johnson and Kimberly Anderson, eighth-grade students at Crutcho Junior High School in Oklahoma City. Both students received a weather radio.

For this meeting's program, Chapter Vice President
Fred Carr introduced Jeff Kimpel, the new director of the National Severe Storms Laboratory (NSSL), who gave a brief overview of the NSSL. According to Kimpel, there are currently 127 people who work at NSSL, with 53 being federal employees and most of the remaining 74 being employees of the Cooperative Institute for Mesoscale Meteorological Studies. Kimpel mentioned some of the honors that have recently been bestowed upon NSSL employees, including the Department of Commerce Gold Medal, which was presented for the first time to an entire laboratory.

Carr introduced Allan Murphy of Prediction and Evaluation Systems in Corvallis, Oregon, and professor emeritus at Oregon State University, who spoke on "The Finley Affair." Murphy explained that in 1884, Sgt. John P. Finley of the U.S. Army Signal Corps published verification statistics for an experimental tornado forecasting program. Finley's results attracted immediate attention and, during the next nine years, stimulated the first substantive developments related to forecast verification. Out of the Finley affair came the initial developments of verification measures that have been rediscovered in more recent years under names such as critical success index, threat score, Kuiper's performance index, and Heidke's skill score. Murphy emphasized that a high-quality forecast requires diagnostic, real-time verification that may be more difficult to produce than the forecast itself. -Rodger A. Brown.

\section{Memphis}

A meeting was held on 11 March 1997 at the Massachusetts Institute of Technology (MIT)-Lincoln Laboratory's Integrated Terminal Weather System (ITWS) office. Eleven people were present.

Members decided that ballots will be mailed out to the membership for the purpose of electing chapter officers for the 1997/98 academic year. David Gaffin volunteered to coordinate the local chapter's role in participation at the science fair in Jonesboro, Arkansas. Chapter Secretary Benjamin G. Boorman volunteered to be a judge at the 43rd Annual MemphisShelby County Science and Engineering Fair.

There were three speakers at the meeting. First, Jeffrey Logsdon of the Memphis NWSFO gave a presentation of new images he has scanned onto the NWS's Web site. The figures include radar images of bow echoes and tornado vortex signatures as well as photos of tornado damage from a day of severe storms that swept across the midsouth on 1 March 1997.

The second presentation was by Bradley A. Crowe 
of the MIT-Lincoln Laboratory Weather Sensing group. Crowe discussed his poster board "The Impact of Thunderstorm Growth and Decay on Air Traffic Management in Class B Airspace," which was presented at AMS's Seventh Conference on Aviation, Range, and Aerospace Meteorology on 2-7 February 1997 in Long Beach, California. He concluded that air traffic control specialists could derive significant benefit from both a growth and a decay product.

The final talk was given by Mark A. Isaminger also from the MIT-Lincoln Laboratory Weather Sensing group. Isaminger discussed recent and future upgrades to the ITWS's Initial Operating Capability products. He also discussed the storm growth and decay demonstration and validation effort that will occur at Memphis during the summer of 1997.-Benjamin $G$. Boorman.

\section{Central Texas}

Members met on 29 March 1997 for a tour of Mansfield Dam on Lake Travis, near Austin. The dam, one of the flood control structures in Texas, forms Lake Travis. It was completed in 1951 with the intention of protecting Austin and the lower Colorado River from flooding. The tour included a look at Mansfield's 24 floodgates as well as a walk through the three miles of tunnels that wind through the inner structure of the dam. Members were also able to see the three hydrogeneration turbines housed within the dam.-Bob Rose.

\section{Western New York}

The Great Lakes were the topic at a recent chapter meeting. Tony Eberhardt of the U.S. Corps of Engineers, Buffalo district, was the guest speaker.

Eberhardt's presentation included a general overview of the hydrology of the entire Great Lakes ba$\sin$. He focused on Lakes Erie and Ontario, which are both under his district's jurisdiction. He mentioned that only two of the Great Lakes have man-made controls-Lakes Superior and Ontario. Eberhardt explained that the principal controls on Lake Ontario are between Kingston and Montreal and involve coordination efforts between two countries (the United States and Canada), one state (New York), and two provinces (Ontario and Quebec). He continued to explain that conflicting interests are involved, such as the power authorities and recreation groups who desire high water levels versus property owners along the lakeshore who want lower levels.
Eberhardt said that no controls exist on Lake Erie because weather conditions can cause extreme seiches. According to Eberhardt, the greatest surge on record was in December 1985 with a slosh of over 16 feet on the lake between Toledo and Buffalo.

Included in the presentation were the operations of the Niagara power plant, which, according to Eberhardt, diverts $50 \%-75 \%$ of the $250000 \mathrm{cfs}$ flow over Niagara Falls and the Mount Morris Dam on the Genesee River.-Steve McLaughlin.

\section{Western Wisconsin}

During the 18 February 1997 meeting, Jeff Sexton, with the Federal Aviation Administration (FAA) La Crosse Airport, spoke about weather and aviation as they relate to the La Crosse area.

Sexton began his presentation by highlighting the variety of weather the La Crosse region experiences throughout the year. He explained that weather observations at La Crosse are taken by FAA personnel during the day and into the evening, with contract observers performing the observations at night.

Sexton mentioned that an ASOS (Automated Surface Observing System) unit is currently being installed at the airport. He also covered the special cloud levels and visibilities crucial to operations at La Crosse and discussed briefly the METAR codes. He concluded the presentation with a description of a typical day at the airport, a summary of air traffic control systems at airports and in airplanes, and a discussion of aircraft icing._-Todd Shea.

\section{Greater St. Louis}

Members and guests convened on 20 February 1997 at the Busch Student Center on the campus of Saint Louis University. Chapter business included attendance at AMS's 77th Annual Meeting, guest speakers, science fair participation, and membership drives.

Gandikota Rao and Chapter President Ron Przybylinski discussed two conferences coming to the St. Louis area during the summer of 1998. One is the GEWEX (Global Energy Water Experiment) Conference, which will be held 8 June with $300-500$ attendees expected. The other is the 27th Conference on Broadcast Meteorology, which is scheduled for $\mathrm{Au}-$ gust 1998.

Chapter Vice President Jim Moore introduced Carol L. Weaver from the Air Weather Service at Scott Air Force Base, Illinois, as the guest speaker for the evening. Weaver's topic was a Cognitive Analysis of Meteorological Tasks (CAMET) study, focusing on 
why forecasts are not any better considering the amount of high-tech equipment.

Weaver described the CAMET study as a collaborative effort to understand cognitive aspects of forecasting. She said that 42 Air Weather Service and 13 NWS forecasters were interviewed for the study. The goals of the study were to better understand knowledge/skills underlying expert forecasting and to identify ways to improve forecast performance.

The focus of the study was cognitive characteristics in the weather field, such as noticing patterns, seeking information and interpreting data, use of visual mental models of the atmosphere, and metacognitive processing (self-evaluation). The study showed that the skill level of forecasters is highly variable due to little opportunity for mentoring, no critiquing time, and high pressure jobs.

Weaver outlined the preliminary recommendations from the study as to expand formal training to include the basics of meteorology, critical thinking skills, and communications skills; increase on-the-job training; provide timely feedback on specific forecasts; and reevaluate the use of current technology, such as integrating multiple weather products and allowing forecasters to directly manipulate the data.-Susan A. Tarbell.

\section{High Plains}

The chapter's first meeting of 1997 was held at Fort Hays State University (FHSU) in Hays, Kansas, on 11 March 1997. The 31 attendees included contingents from the four participating NWS offices in Dodge City and Goodland, Kansas; and North Platte and Hastings, Nebraska. Also in attendance were Roger Pruitt of FHSU, the guest speaker Eric Rasmussen, several Hays area guests, David Blanchard of NSSL, and Brian Motta of Colorado State University.

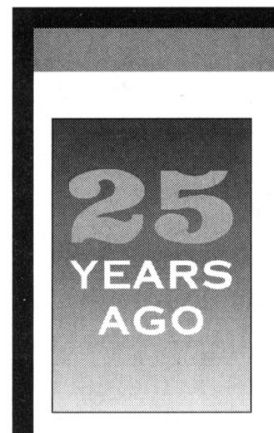

\section{Snow Redistribution Experiment Reports}

Because nature failed to cooperate in providing Lake Erie snowstorms for scientists to seed this winter, scientists from the National Oceanic and Atmospheric Administration have not yet been able to determine the feasibility of seeding to redistribute snowfall. NOAA's planned program, directed by Dr. Helmut K. Weickmann (see Bulletin, 51, 1176), was to seed and modify major lake storms to find out if it is possible to spread lake snowfall over a larger land area in such a way that the snow burden is reduced along the shore belt.

Although there were no seedable storms during the winter, the scientific team was able to study the basic reactions of certain cloud systems to seeding with silver iodide crystals. Seedings were conducted on 22 and 30 November over the U.S. side of Lake Erie using a DC-6 meteorological aircraft operated by NOAA Research Flight Facility.

On 22 November a convective, unstable cloud layer with bases at $610 \mathrm{~m}$ and tops between 1524 and $2134 \mathrm{~m}$ and a temperature of about $-11.5^{\circ} \mathrm{C}$ at the top was seeded with a silver iodide generator. After seeding in a racetrack shaped pattern $12 \mathrm{mi}$ long and $2 \mathrm{mi}$ wide, water vapor in the clouds immediately began to transform into ice crystals. Mobile ground units under the seeded clouds observed large numbers of needle-shaped crystals and star-shaped aggregates of crystals.

On 30 November relatively stable clouds of six distinct layers from about $518 \mathrm{~m}$ at $-6.5^{\circ} \mathrm{C}$ to $3018 \mathrm{~m}$ at $-13.8^{\circ} \mathrm{C}$ were seeded. A mobile unit in the target area observed normal rimed snow stars change within minutes to great numbers of tiny individual snow pellets as the seeding pattern drifted over the observation site. There was about a 1000 -fold increase in the numbers of snow crystals.

Dr. Weickmann also reported observation of an intensive seeding effect due to pollution downwind of local industrial complexes. The Cornell Aeronautical Laboratories of Buffalo, working under a NOAA contract, provided a network of 52 snowgages for the project.

Bull. Amer. Meteor. Soc., 53, 463. 
Eric Rasmussen of the National Severe Storms Laboratory (NSSL) provided the program with an overview of the early stages of research conducted by VORTEX (Verification of the Origins of Rotation in Tornadoes Experiment). He presented some of the discoveries made when studying the Dimmit, Texas, tornado in 1995. Rasmussen explained that a few of the theories involving tornadogenesis are going to have to be thought through again in light of some surprising discoveries with the Dimmit storm. He stressed that the research work is in the very early stages. So far, only one of the storms that VORTEX collected data on has been studied, and said Rasmussen it is still premature to make any conclusions.

At the conclusion of Rasmussen's presentation, the chapter held a short business meeting including elections for the coming year. The 1997 High Plains chapter officers are Jim Johnson, NWS Dodge City, president; Matt Gerard, NWS Dodge City, vice president; Jim Brewster, NWS Hastings, treasurer, Bruce Entwistle, NWS Goodland, secretary; and Stephen Parker, NWS North Platte, officer without portfolio.

A proposal to sponsor the first rotating annual September meeting was submitted by the NWS Dodge City, Kansas, office. The proposal was accepted by the membership. The Dodge City office will host a three-day conference 15-17 September 1997. This will be the High Plains chapter's first conference with a chosen topic of NWS modernization issues. Sessions will include 1) technology advances, 2) mesoscale forecasting advances and methodology, 3) local watch issuance, and 4) management and personnel issues. The call for papers has been issued with abstracts due by 15 July 1997. Authors should submit one-page abstracts to the chapter president via e-mail at jim.johnson@noaa.gov.

A discussion concerning supporting local science fairs ensued. A committee was formed to investigate how to approach area science fairs from a chapter perspective. Overseen by the vice president, the committee includes Rick Ewald, SOO, NWS Hastings, Nebraska, and the chapter secretary.-Jim Johnson.

\section{Los Angeles}

Chapter members met at the South Coast Air Quality Management District headquarters in Diamond Bar, California, where Shankar Prasad, health effects officer, spoke about "Air Pollution Impacts on Human Health: Nature and Extend" for the March meeting.

Prasad reviewed studies showing the health effects of increased levels of PM10 and ozone. One study estimated that a $10 \mu \mathrm{g} \mathrm{m}^{-3}$ increase in PM10 increases mortality $1 \%$, respiratory ailments $3.4 \%$, cardiovascular ailments $1.4 \%$, asthma $3 \%$, and possibly shortens life by one to three years. He said that ozone also shows similar effects such that the threshold level for safety is unknown.

Prasad, while pointing out the hazards of these pollutants to human health, also criticized some of the published results as being extremely difficult to substantiate due to the complexities in health studies and especially variations in human susceptibility. He stated that the Environmental Protection Agency has proposed more stringent standards for ozone and particulates with attainment deadlines for Los Angeles set at the year 2010 for ozone and 2006 for PM10.

Several members were able to attend the 77th AMS Annual Meeting in Long Beach, as well as help with registration. Robert Quayle, chief of the Global Climate Laboratory, National Climatic Data Center, was the guest speaker at the February meeting, which was held during the Annual Meeting. Quayle presented a lecture on "Global Surface Temperatures and Trends from Various Sources."

Quayle compared several different datasets in looking for evidence of global warming. In general, he said, most sources show a slow warming trend for the 1850 present period, though the magnitude differed. Corrections for urban heat islands and continental biases were discussed as well as the integrity of the data. Global precipitation also was shown to be increasing slowly.-Steve LaDochy.

\section{Central Louisiana}

Frank Rebitte, warning coordination meteorologist at the NWS in Slidell, was the guest speaker on 19 March 1997. Revitte discussed the groundwork for persons interested in becoming official NWS volunteer severe weather observers. He began his presentation by stating the NWS operational meteorologists depend on local volunteer observers for supplemental data, especially with regard to isolated severe weather and resulting damage, that radar systems cannot provide. Revitte's classroom setting included discussion, photo slides, and videos.-Jeff Hardy.

\section{Lakota}

The first meeting for the newly implemented chapter was held on 20 February 1997. Fifteen people were present. Vic Jensen conducted the business portion of the meeting, which included discussions about AMS chapter guidelines, committee possibilities, program 
activities, general chapter guidelines, chapter dues, membership drives, and guest speakers. The first elections were held and Vic Jensen was elected president, John Paul Martin was elected vice president, Darin Langerud was elected treasurer, and Tanya Fransen was elected secretary.-Tanya Fransen.

\section{Denver-Boulder}

On 20 February 1997, chapter members convened at the NCAR Table Mesa Lab to gain some historical perspective concerning meteorology. A local snowstorm of incorrectly forecast intensity did not deter 16 members from hearing a presentation from three chapter members entitled "Looking Back: Satellites, Planes, Trains, and Balloons."

Ralph Anderson, who was associated for 30 years with the U.S. Weather Bureau/ESSA/NOAA satellite program, started off the presentation by explaining how TIROS pictures were first used operationally at the National Meteorological Center (NMC) in the 1960s. TIROS pictures were manually converted into nephanalyses at satellite read out stations and then sent by fax to NMC. Once there, Anderson said that individual nephanalyses were traced onto acetate overlays for use in analyzing Northern Hemisphere surface and upper-air charts. Compositing the nephanalyses facilitated the interpretation of synoptic-scale cloud systems since individual satellite passes showed only portions of storms. Anderson showed examples of the early TIROS data and an example of what is possible with today's operational work station, which can provide remapped satellite imagery with analysis overlays constructed from model output grid data.

\section{Local Chapter Web Site Addresses}

\section{Cape Canaveral:}

http://sunmlb.nws.fit.edu:80/ams.html

\section{Chicago:}

http://taiga.geog.niu.edu/nwslot/ams.html

\section{Central Louisiana:}

http://www.srcc.lsu.edu/ igrymes/AMS/

\section{Central Oklahoma:}

http://www.nssl.noaa.gov/cocams

\section{Colorado State University:}

http://www.atmos.colostate.edu/html/SocialDir/ams.html

\section{Denver-Boulder:}

http://www.cgd.ucar.edu/stats/ams/dbams.html

\section{District of Columbia:}

http://wxnet4.nbc4.com/dcams/indexdcams.html

\section{Houston:}

http://www.srh.noaa.gov: 80/ftproot/hgx/html/ indexl/amsl/amsl.htm

\section{Memphis:}

http://www.srh.noaa.gov/ftproot/meg/html/index.html

\section{New York City/Long Island:}

http://www.nws.bnl.gov/meetings.html

\section{Northwest Ohio:}

http://norden l.com/ rdale/ams.html
Northern Illinois University:

http://taiga.geog.niu.edu/weather/ams.html

\section{Plymouth State College:}

http://oz.plymouth.edu:80/ meteo/home.html

\section{Siouxland Weather MINDS:}

http://physics.sdstate.edu/wx_minds/wxminds.htm

State University of New York at Brockport:

http://www.weather.brockport.edu:80/ams/

\section{Upstate South Carolina:}

http://tgsv5.nws.noaa.gov/er/gsp/ams.htm

University of Alabama in Huntsville:

$\mathrm{http}: / /$ www.atmos.uah.edu/essl/ams/vah_ams_home.html

University of North Carolina at Asheville:

http://vortex.atms.unca.edu/ams/index.html

\section{University of North Dakota:}

http://www.aero.und.edu:80/Student-Organizations/AMS/ index.html

\section{University of Oklahoma:}

http://www.ou.edu/student/tornado/

\section{University of Wisconsin-Madison:}

$\mathrm{http}: / /$ www.meteor.wisc.edu/uw-aos/ams-uwmad.html

Wright Memorial:

http://weather.lab.wpafb.af.mil/ams/ 
Loren Crow followed, recounting some highlights of his career during World War II and the following years. One of his tasks while stationed in Guam in 1944 was to forecast cloud-free conditions for a photo reconnaissance flight over Okinawa, Japan. For this he explained that he used the historical series Northern Hemisphere surface weather maps and applied techniques learned at Cal Tech. $\mathrm{He}$ also recounted later experiences in England where he successfully forecast for pigeon races and also solved a problem for the British Railways, which was caused by frost coating the third rail of a commuter line.

Vincent Lally completed the presentation with some remarks on ballooning. Lally is a pioneer in scientific ballooning and founded and directed the NCAR balloon facility. He reviewed the history of super pressure balloons and the GARP experiments and then discussed current attempts to complete round-theworld manned balloon flights. He attributed recent failures to the psychology of the balloonists who insisted on trying to actively fly the balloons rather than just going along for the ride. He suggested that recent attempts have failed do to inadequate planning and a failure of the balloonist to "do their math."

The March meeting was hosted by AMS corporate member Radian International at its factory near the Boulder airport. Eighteen members listened to Gene Pfeffer, head of the Radian Electronics Division in Boulder, explain the company's Doppler radar lower atmospheric wind profiling system and the Radio Acoustic Sounding System (RASS) temperature profiler.

Pfeffer reviewed the basics of profiling and profile design. According to Pfeffer, Radian manufactures and fields wind profilers in the VHF and UHf range, which provide vertical profiles of horizontal wind speeds and direction, and vertical velocity reliably to ranges of 3 to $16 \mathrm{~km}$ depending on design. A second remote sounding technology, RASS, provides virtual temperature profiles up to $2 \mathrm{~km}$ depending on atmospheric conditions.

The meeting included a tour of the Radian factory, a demonstration of current production models, and an inspection and description of new systems under development. Since 1991, Radian and Senoma Technology, Inc., have had a cooperative research and development agreement with NOAA to commercialize this NOAA-developed remote sensing technology, which was invented in Boulder.-Ralph Anderson.

\section{District of Columbia}

Gene Rasmussen, AMS president-elect, was the guest speaker at the February meeting. Rasmussen, a senior research scientist in the Department of Meteorology at the University of Maryland, presented approximately 30 meeting attendees with a look at how the science of hydrology has evolved during the last 40-50 years in, "The Development of Our Understanding of North American Hydrology over the Past Half Century."-Mary Scarzello.

Approximately 25 people attended the 18 March 1997 meeting held at NOAA's Silver Spring Metro Center 2.

During the brief business part of the meeting, Chapter Chairman Bob Showalter mentioned that it is time to form an election committee and he urged members to volunteer for both the committee and to run for office. Next, Showalter introduced the new acting recording secretary, Lt. Col. Lauraleen O'Connor. O'Connor is the Air Force User Liaison to NOAA/ NESDIS/IPO, which is the Integrated Program Office for the National Polar-Orbiting Operational Environmental Satellite System (NPOESS/IPO). The Chapter Representative at Large Col. Dan McMorrow stated that the chapter had been asked to participate in 11 science fairs; 7 of which have occurred. He thanked the volunteer judges and stated that he needs three judges per fair for the remaining events. McMorrow also asked for help with the banquet meeting, which is planned for the second or third week of June at the University of Maryland. Kurt Alexander gave an overview of a few interesting WWW sites.

Chapter Vice Chairperson Ward Seguin introduced the evening's guest speakers, Glen Austin, deputy chief of the NWS Office of Hydrology's Operations Division, and Jeff Zimmerman, hydrologist and AWIPS Focal Point. Austin gave an overview of recent flood disasters, the spring 1997 flood outlook, and improvements in hydrological Services; Zimmerman followed with a technology demonstration.

Austin showed a 31 December 1996 GOES-9 image of the "Pineapple Express," which brought $20+$ inches of precipitation (rain, snow, and ice) to the Pacific Northwest. As a result, the Lake Tahoe, California, water level was at its highest level since 1917. Austin said that this event cost the region an estimated $\$ 1.5$ billion and resulted in 36 deaths. Austin also profiled the 1 March 1997 event in the Ohio Valley, during which 9-13 inches of rain fell in 36 hours, resulting in $\$ 0.75$ billion (and rising) in damages and 20 
deaths across West Virginia, Ohio, Kentucky, and Tennessee. The precipitation records indicated that it was the wettest March on record for Louisville, Kentucky. Despite the damages, the residents of Falmouth, Kentucky were given enough lead time to evacuate the town's 2700 residents.

Austin discussed this year's flood potential using a NOAA/NWS graphic of Flood Potential, as of 14 March 1997. The graphic indicates that North Dakota and South Dakota are predicted to have flood potential well-above average, whereas the Pacific Northwest, Mississippi Basin, and Ohio Valley are expected to have above average flood potential.

The Office of Hydrology makes up about $10 \%$ of NWS personnel. As part of the NWS modernization, staffing has increase at the field sites, 8-hour operations have increased to 16-hour, and there is more coordination between meteorologists and hydrologists. Austin briefly addressed the new tools and techniques coming on line at the river forecast centers: NWS River Forecast System, Precipitation Prediction System, Advanced Hydrologic Prediction System, and the Interactive Forecast Model. Zimmerman gave a brief technology demonstration of some of these new products.

Following the speakers' presentations, Fred Hamberg won the NOAA weather radio.-Lauraleen O'Connor.

\section{Texas A\&M University}

The third and fourth meetings of the spring 1997 semester were held 25 March and 8 April 1997 on the Texas A\&M University (TAMU) campus.

The third meeting featured TAMU professors Gerald North, Thomas Wilheit, John NielsenGammon, Neil Tindale, and Michael Biggerstaff. They each talked about their professional and educational backgrounds and current research projects.

Kelly Findeisen, chapter president, discussed routine business including upcoming officer elections and the departmental picnic. Chapter Undergraduate Representative Adam Houston encouraged undergraduates to submit nominations for the Robert C. Runnels Excellence in Advising Award.

Bill Read, meteorologist in charge at the Houston/ Galveston NWSFO, was the featured speaker at the fourth meeting. He discussed operational changes during his career at the NWS and provided a glimpse of the future of the NWS. Read also presented slides showing the layout of the Houston office. Findeisen discussed possible summer job opportunities and encouraged members to look at the AMS Web site for more information.-Lori Grimm.

\section{Cape Canaveral}

The speaker at the January meeting was Chris Landsea. Landsea gave a presentation titled "Are We Seeing a Long-Term Upturn in Major Hurricane Activity?"

The February meeting involved a trip to the Channel 2 television studios in Orlando. Dave Marsh is Channel 2's lead meteorologist and he talked to the chapter about the television meteorologist profession. He then led a tour of the news and weather center facilities at Channel 2.

In March Mark Moldwin of the Department of Physics and Space Sciences at the Florida Institute of Technology in Melbourne gave a talk entitled "What's New in Atmospheric Electricity: Sprites, Jets, TIPPs, and Elves." He discussed the recently discovered phenomenon of lightning striking out into space from the tops of cumulonimbus clouds.-Dave Biggar.

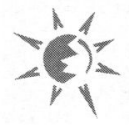

\section{NEW PUBLICATION}

\section{Atmospheric Technology Directory and Buyer's Guide}

1997 EDITION

- Information You Need •

Corporations

Government Agencies

Products and Services

Internet Links

CHECK THE METEOQUEST WEB SITE http://www.mqinc.com

or contact

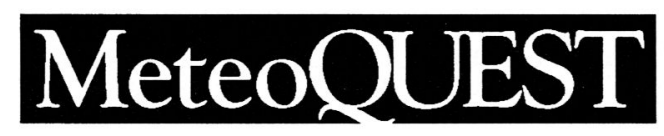

P.O. Box 10360

Bedford, $\mathrm{NH} 03110-0360$

Tel: (603) 471-1802 Fax: (603) 471-1803

e-mail: mqinc@mqinc.com 